\title{
Komunikasi dan Media Sosial (Communications and Social Media)
}

\author{
Errika Dwi Setya Watie \\ (errikadwisw@yahoo.com) \\ Dosen Jurusan Ilmu Komunikasi Universitas Semarang
}

\begin{abstract}
Media presents to be a part of human life. The presence and the development of internet bring a new way of how to communite in social life. Social media presents and changes the communication paradigm in today's society. Communication in social media is not limited by distance, time, and space. It could happen anywhere, anytime, without having a face to face talking. Even social media can negate social status that is often as a barrier in communication.

Social media has changed the world. Levels of communication merged into one container called a social media. The rise of many consequences must also be wary of, in the sense of social media opens up the opportunity of each individual involved in it to issue his opinion freely. However, self-control should be shared, in order to have freedom of communication which does not violate ethical boundaries and does not offend others.
\end{abstract}

Kata Kunci : Komunikasi, Media social.

\section{PENDAHULUAN}

Masyarakat modern saat ini hampir tidak mungkin tidak terkena paparan media. Disadari atau tidak, media dengan segala kontennya hadir menjadi bagian hidup manusia. Seiring dengan perkembangan jaman, kehadiran media makin beragam dan berkembang.

Awalnya komunikasi dalam media berjalan hanya searah, dalam arti penikmat media hanya bisa menikmati konten yang disajikan sumber media. Namun seiring perkembangan jaman, orang awam sebagai penikmat media tidak lagi hanya bisa menikmati konten dari media yang terpapar padanya, namun sudah bisa ikut serta mengisi konten di media tersebut.

Muncul dan berkembangnya internet membawa cara komunikasi baru di masyarakat. Media sosial hadir dan merubah paradigma berkomunikasi di masyarakat saat ini. Komunikasi tak terbatas jarak, waktu, ruang. Bisa terjadi dimana saja, kapan saja, tanpa harus tatap muka. Bahkan media sosial mampu meniadakan status sosial, yang sering kali sebagai penghambat komunikasi. Dengan hadirnya Twitter, Facebook, Google+ dan sejenisnya, orang-orang tanpa harus bertemu, bisa saling berinteraksi. Jarak tak lagi menjadi masalah dalam berkomunikasi. Lama waktu terakhir bertemu pun juga tak lagi menjadi masalah. Teman yang telah 20 tahun tak bertemu pun bisa saling menemukan dan menjalin komunikasi lagi. Dan karena kemudahan penggunaannya, hampir bisa dikatakan, siapa saja bisa mengakses dan memanfaatkan media sosial.

Media sosial telah banyak merubah dunia. Memutarbalikkan banyak pemikiran dan teori yang dimiliki. Tingkatan atau level komunikasi melebur dalam satu wadah yang disebut jejaring sosial/media sosial. Konsekuensi yang muncul pun juga wajib diwaspadai, dalam arti media 
sosial semakin membuka kesempatan tiap individu yang terlibat di dalamnya untuk bebas mengeluarkan pendapatnya. Akan tetapi kendali diri harusnya juga dimiliki, agar kebebasan yang dimiliki juga tidak melanggar batasan dan tidak menyinggung pihak lain.

\section{KOMUNIKASI}

Mendefinisikan kata komunikasi sebenarnya tidaklah semudah kelihatannya. Orang dengan masingmasing latar belakangnya, bisa mendefisikan kata komunikasi dengan cara yang berbeda. Dalam hal ini definisi dibutuhkan tentunya untuk membantu studi yang dilakukan. Simbol dalam "bahasa" komunikasi adalah sesuatu yang digunakan untuk menunjukkan sesuatu yang lain, berdasarkan kesepakatan kelompok orang. (Sobur, 2006 : 157). Karena itu kata komunikasi disini dipahami sebagai proses manusia merespon perilaku simbolik dari orang lain. (Adler \& Rodman, 2006: 4). Bahasa, kata, gesture, tanda, merupakan bagian dari symbol yang digunakan manusia dalam mendefinisikan sesuatu atau menyampaikan sesuatu ke orang lain. Sehingga bagaimana bahasa, kata, gesture, tanda digunakan manusia adalah apa yang dipelajari dalam ilmu komunikasi, termasuk juga bagaimana implikasi yang muncul dari penggunaan berbagai symbol tersebut.

Komunikasi yang dilakukan manusia berjalan di berbagai level komunikasi. Mulai dari komunikasi intrapersonal, komunikasi interpersonal, komunikasi kelompok, komunikasi publik, hingga komunikasi massa. Komunikasi massa merupakan level komunikasi terbesar, dimana cakupan sasaran komunikasinya bisa dikatakan terbanyak, orang yang terlibat didalamnyapun juga terbanyak.
Komunikasi massa terdiri dari pesanpesan yang ditransmisikan ke sasaran audience yang benyak dan tersebar luas, dengan menggunakan Koran, majalah, televisi, radio, dan internet. (Adler \& Rodman, 2006: 8). Sehingga bisa dikatakan, media-media yang digunakan dalam menyampaian pesan dalam komunikasi massa disebut sebagai media massa.

\section{MEDIA SOSIAL}

New media merupakan media yang menawarkan digitisation, convergence, interactiviy, dan development of network terkait pembuatan pesan dan penyampaian pesannya. Kemampuanya menawarkan interaktifitas ini memungkinkan pengguna dari new media memiliki pilihan informasi apa yang dikonsumsi, sekaligus mengendalikan keluaran informasi yang dihasilkan serta melakukan pilihan-pilihan yang diinginkannya. Kemampuan menawarkan suatu interactivity inilah yang merupakan konsep sentral dari pemahaman tentang new media. (Flew, 2002: 11-22)

Munculnya virtual reality, komunitas virtual identitas virtual merupakan fenomena yang banyak muncul seiring dnegan hadirnya new media. Fenomena ini muncul karena new media memungkinkan penggunanya untuk menggunakan ruang seluas-luasnya di new media, memperluas jaringan seluas-luasnya, dan menunjukkan identitas yang lain dengan yang dimiliki pengguna tersebut di dunia nyata. (Flew, 2002: 25)

Sebutan media baru/ new media ini merupakan pengistilahan untuk menggambarkan kerakteristik media yang berbeda dari yang telah ada selama ini. Media seperti televisi, radio, majalah, koran digolongkan menjadi media lama/ old media, dan media internet yang mengandung muatan 
interaktif digolongkan sebagai media baru/ new media. Sehingga pengistilahan ini bukan lah berarti kemudian media lama menjadi hilang digantikan media baru, namun ini merupakan pengistilahan untuk menggambarkan karakteristik yang muncul saja.

Media sosial/ social media atau yang dikenal juga dengan jejaring sosial merupakan bagian dari media baru. Jelas kiranya bahwa muatan interaktif dalam media baru sangatlah tinggi. Media sosial, dikutip dari Wikipedia, didefinisikan sebagai sebuah media online, dengan para penggunanya bisa dengan mudah berpartisipasi, berbagi, dan menciptakan isi meliputi blog, jejaring sosial, wiki, forum dan dunia virtual. Blog, jejaring sosial dan wiki merupakan bentuk media sosial yang paling umum digunakan oleh masyarakat di seluruh dunia.

(http://id.wikipedia.org/wiki/Media_sos ial).

Ardianto dalam buku Komunikasi 2.0 mengungkapkan, bahwa media sosial online, disebut jejaring sosial online bukan media massa online karena media sosial memiliki kekuatan sosial yang sangat mempengaruhi opini publik yang berkembang di masyarakat. Penggalangan dukungan atau gerakan massa bisa terbentuk karena kekuatan media online karena apa yang ada di dalam media sosial, terbukti mampu membentuk opini, sikap dan perilaku publik atau masyarakat. Fenomena media sosial ini bisa dilihat dari kasus Prita Mulyasari versus Rumah Sakit Omni International. Inilah alasan mengapa media ini disebut media sosial bukan media massa. (Ardianto, 2011: xii)

\section{DUNIA VIRTUAL}

Tak bisa dipungkiri jika kemajuan teknologi informasi saat ini justru menggiring masyarakat global ke arah akhir sosial. Alan Touraine melihat bahwa proses akhir sosial ini sebagai akibat modernisasi yang telah mencapai titk ekstrimnya dewasa ini, yang disebut sebagai hipermodernisasi kontemporer. Proses sosial ini kini dipercepat dan mencapai keadaan maksimal di tangan media internet yang menciptakan berbagai informasi relasi sosial. Realitas yang ada ini membuat individu-individu penikmatnya seolah saling berlomba dalam sebuah arena duel, kontes tantangan, rayuan, dan godaan masyarakat konsumer. (Piliang, 2004:233)

Akhir sosial juga ditandai oleh transparasi sosial, yaitu satu kondisi lenyapnya kategori sosial, batas sosial, hirarki sosial yang sebelumnya membentuk suatu masyarakat. Jaringan informasi menjadi bersifat transparan dan virtual tatkala tak ada lagi kategorikategori moral yang mengikatnya dan ukuran-ukuran nilai yang membatasinya. Party-line merupakan gambaran masyarakat cyber kita yang tenggelam di dalam ekstasi komunikasi. Orang yang terbuai dalam komunikasi di dalam dunia cyber bisa tenggelam di dalamnya dan terbawa arus gaya komunikasi yang ada, hingga tak jarang bisa seolah menjadi sosok lain, yang jauh beda dengan dunia nyatanya. (Piliang, 2004:234-235)

Terpaan media, interaksi dalam media di abad informasi saat ini, seringkali membuat diri orang yang terlibat di dalamnya tak lebih dari bentukan media. Christoper Wulf dalam artikelnya "The Temporaly of WorldView dan Self Image, mengatakan bahwa pandangan dunia dan citra diri memang tak bisa dipisahkan. Cara manusia memandang dunia dalah cara menusia memandang dirinya, dan cara manusia memahami dirinya adalah cara manusia memahami dunia. Heidegger, dalam artikelnya "The Age Of World 
Picture" mengungkapkan bahwa dengan berkembangbiaknya citraan di dunia, maka dunia tempat manusia hidup tak lebih dari sebuah ontology citraan. Citraan-citraan yang disajikan media, pada akhinya menjadi cermin tempat kita berkaca, menunjukkan ekssistensi kita. (Piliang, 2004:166167). Kehadiran dunia virtual semakin mengukuhkan citraan-citraan yang dibentuk ini.

Memang tak bisa dipungkiri, bahwa manusia modern saat ini sangat tergantung hidupnya pada teknologi. Kehadiran internet yang diikuti dengan munculnya media sosial di dalamnya membawa pula berbagai masalah etika berkomunikasi. Penggunaan identitas palsu untuk kepentingan yang "negatif", penyebaran dan pengunduhan materi yang dilindungi hak cipta atau materi yang dilarang, merupakan hal yang melanggar etika dan dilarang. Namun kebebasan yang ditawarkan internet terutama dalam hal ini media sosial, seolah membuat matinya kepekaan etika. Apa yang harusnya tidak dilakukan, menjadi "nampak wajar" dilakukan. Bahkan tak jarang ada yang menganggapnya bukan suatu kesalahan dengan berbekal berbagai pembenaran yang dimunculkan.

Dunia virtual akhirnya membawa fatamorgana, ilusi realita bagi setiap pengguna yang tak memiliki kendali diri. Tentunya konsep diri berpengaruh disini. Konsep diri merupakan seperangkat persepsi yang relatif stabil yang dipercaya seseorang mengenai dirinya sendiri. Mead berpendapat bahwa karena manusia memiliki konsep diri, maka mereka memiliki mekanisme untuk berinteraksi dengan dirinya. Artinya ketika konsep diri seseorang bahwa dia adalah orang yang memegang etika dalam berinteraksi dan berkomunikasi dengan orang lain, maka orang tersebut akan mampu mengendalikan dirinya untuk tidak menerjang batasan etika yang ada. Mekanisme terkait konsep diri ini digunakan untuk menuntun perilaku dan sikap yang ditampilkannya (West \& Turner, 2008: 102-103). Walau memang tak bisa dipungkiri pengaruh lingkungan sosial dan budaya juga berperan dalam menentukan bagaimana seseorang akan berperilaku dan bersikap.

Darmastuti, dalam buku Komunikasi 2.0, mengutip pernyataan Stanley J Baran dan Edward T Hall, bahwa komunikasi adalah dasar dari suatu budaya. Komunikasi dan budaya adalah pasangan tak terpisahkan. Perubahan pada salah satu sisi akan merubah sisi yang lainnya. Darmastuti menambahkan bahwa komunikasi dengan media sosial akan membawa pengaruh pada:

1. Kepercayaan, nilai, dan sikap

2. Pandangan dunia

3. Organisasi sosial

4. Tabiat manusia

5. Orientasi kegiatan

6. Persepsi diri dan orang lain

(Darmastuti, 2011: 218)

\section{LEVEL KOMUNIKASI DALAM MEDIA SOSIAL}

Level komunikasi terdiri dari komunikasi intrapersonal, komunikasi interpersonal, komunikasi kelompok, komunikasi publik, dan komunikasi massa. Tiap level komunikasi memiliki cirri dan karakter tersendiri. Utari dalam Komunikasi 2.0, menyatakan, bahwa perkembangan media baru membawa konsekuensi pergeseran dan perubahan dalam teori-teori komunikasi massa. Karakteristik media yang selama ini dikenal, melebur dalam media baru. Ini karena terbentuknya mass-self comunication. Dalam media baru ada kombinasi antara komunikasi interpersonal dengan komunikasi massa. 
Karena menjangkau khalayak secara global maka bisa dikatakan komunikasi massa, dan pada saat yang sama karena pesan yang ada dibuat, diarahkan, dan dikonsumsi secara personal, maka dikatakan komunikasi interpersonal. (Utari, 2011:52-53)

Komunikasi

merupakan dipahami sebagai komunikasi yang melibatkan dua orang atau komunikasi yang secara kontekstual merupakan komunikasi interpersonal. Komunikasi interpersonal secara kontekstual memang sangat berbeda dari komunikasi kelompok, meskipun terjadi dalam kelompok kecil. Komunikasi interpersonal mensyaratkan keterlibatan penuh pihak yang terlibat. Jika salah satu pihak menarik diri dari percakapan maka komunikasi interpersonal pun praktis akan berakhir. Jelas, kondisi ini juga berlaku di media sosial. Dalam media sosial, komunikasi tak terjadi secara interaktif jika pihak yang diajak berkomunikasi menarik diri dari percakapan yang ada. Jika pertukaran informasi tidak terjadi, maka pihak pemberi informasi, dalam hal ini pemilik akun media sosial hanya melakukan komunikasi searah, namun begitu ada pihak lain yang menanggapi apa yang dituliskannya dan terjadi interaksi maka komunikasi interpersonal terjadi. (Adler \& Rodman, 2006:188189)

Bagi banyak orang, online communication justru mempermudah terbentuknya hubungan interpersonal yang dekat. Karena melalui komunikasi secara online, tiap individu yang terlibat cenderung lebih berani mengungkapkan pendapatnya, dan membuka dirinya untuk lebih dikenal orang lain. Komunikasi dalam media sosial tak terikat waktu, siang ataupun malam, pihak yang terlibat didalamnya tetap bisa terlibat aktif. Juga tak terikat ruang, dengan siapapun di penjuru dunia pihak yang terlibat di dalamnya bisa berkomunikasi. Hal ini tak mungkin dilakukan dalam kontak tatap muka, termasuk juga jika menggunakan media komunikasi konvensional seperti telepon, hal ini terkait dengan biaya dan perbedaan waktu. Komunikasi secara online dalam hal ini dilihat lebih murah, cepat, dan mudah. (Adler \& Rodman, 2006:189-190).

Komunikasi massa, merupakan level komunikasi terbesar dengan cakupan sasaran komunikasi terbanyak. Komunikasi massa terdiri dari pesanpesan yang ditransmisikan ke sasaran audience yang benyak dan tersebar luas, dengan menggunakan koran, majalah, televisi, radio, dan internet. (Adler \& Rodman, 2006: 8). Kondisi ini juga ditemui dalam media sosial. Apa yang diungkapkan seseorang dalam media sosial, akan bisa dilihat khalayak banyak, sehingga komunikasi massa terjadi.

Dalam media sosial, komunikasi interpersonal dan komunikasi massa melebur menjadi satu. Saat seseorang mengunggah sesuatu kemudian ditanggapi pihak lain, lalu terjadi interaksi, maka komunikasi interpersonal terjadi. Disaat yang sama, saat seseorang mengunggah sesuatu, apa yang diunggahnya bisa dilihat dan dinikmati khalaak banyak, sehingga pada saat yang sama komunikasi massa juga terjadi, sebab komunikasi massa tidak mensyaratkan adanya keterlibatan aktif semua pihak.

\section{PENUTUP}

Dengan kehadiran dunia virtual, membuka kesempatan tiap pihak yang terlibat untuk mengeksistensikan dirinya dengan lebih luas. Apalagi bagi mereka yang aktif di social media. Melalui status, komentar, notes, dan berbagai fasilitas dalam social media tersebut banyak orang berusaha 
menunjukkan keberadaannya dengan terus meng-update segala perkembangan yang ada. Suatu perkembangan yang jika di dunia nyata tak mungkin disampaikan, maka di dunia Social Media, perkembangan ini bisa menjadi konsumsi publik secara umum.

Komunikasi dalam media sosial menjadi lebih kompleks. Dua level komunikasi melebur menjadi satu. Komunikasi interpersonal melebur dengan komunikasi massa. Pada saat orang mengunggah sesuatu, dan terjadi interaksi dengan pihak lain, maka komunikasi interpersonal terjadi, dan disaat yang sama terjadi juga komunikasi massa, sebab apapun yang diunggah bisa langsung dinikmati dan dilihat khalayak banyak.

Dengan kenyataan bahwa apa yang bersifat pribadi bisa menjadi konsumsi publik tersebut, membuat kehadiran media sosial kiranya perlu diperhatikan lagi. Bukan untuk menghentikan perkembangannya, tapi untuk memaksimalkan penggunaannya. Kesadaran diri setiap pengguna penting untuk ditingkatkan, mengingat apa yang diunggah akan bisa mempengaruhi citra diri, dan apa yang diunggah bisa berpengaruh pada hubungan yang terjalin dengan pihak lain.

Kebebasan berpendapat, keleluasaan berbagi yang ditawarkan media sosial hendaknya bisa disikapi secara bijak oleh penggunanya. Dengan tetap berpegang pada etika komunikasi yang kuat, maka kendali diri niscaya akan bisa didapatkan. Kesadaran bahwa konten yang telah diunggah ke internet termasuk di media sosial, pada dasarnya telah menjadi milik umum. Sehingga kewaspadaan dan mawas diri sangat dibutuhkan ketika kita bertukar atau menyebarkan informasi. Dengan kata lain komunikasi di media sosial memang menjadi lebih luas dan leluasa, namun keleluasaan tersebut haruslah tetap terkendali, agar manfaat yang ada bisa dinikmati dengan lebih maksimal.

\section{DAFTAR PUSTAKA}

Aspikom, Komunikasi 2.0, Yogyakarya: Mata Padi Pressindo, 2011.

Burton, Graeme, Media dan Budaya Populer, Yogyakarta: Jalasutra, 2008.

Flew, Terry, New Media: An Introduction. New York: Oxford University Press, 2002.

Griffin, E.M. A First Look At Communication Theory. Sixth Edition. New York: McGraw Hill, 2006.

Littlejohn, S.W \& Karen A. Foss, Theories of Human Communication, Eight Edition, USA: Thomas Wadsworth, 2005.

Piliang, Yasraf Amir. Dunia Yang Dilipat. Yogyakarta: Jalasutra, 2004.

Sobur, Alex, Semiotika Komunikasi, Bandung: Remaja Rosdakarya, 2006.

Ronald B. Adler \& George Rodman, Understanding Human Communication, New York: Oxford University Press, 2006.

West, Richard \& Turner, Lynn H, Pengantar Teori Komunikasi:Analisis dan Aplikasi (Introduction Communication Theory: Analysis and Application, Jakarta: Salemba Humanika, 2008.

http://teknologi.kompasiana.com/intern et/2012/02/12/jejaring-sosialmenggantikan-komunikasi-faceto-face/ - diakses tanggal 28 Februari 2012

http://id.wikipedia.org/wiki/Media_sosi al - diakses tanggal 28 Februari 2012 
